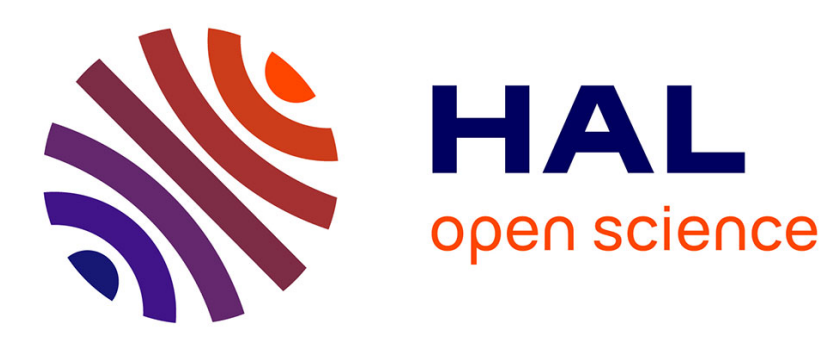

\title{
Toward Physical Internet-Enabled Supply Chain and Logistics Networks in Developing Countries
}

\author{
Sam Ban, Matthieu Lauras, Sarot Srang
}

\section{To cite this version:}

Sam Ban, Matthieu Lauras, Sarot Srang. Toward Physical Internet-Enabled Supply Chain and Logistics Networks in Developing Countries. PRO-VE 2020 - 21st Working Conference on Virtual Enterprises, Nov 2020, Valence, Spain. pp.379-389, 10.1007/978-3-030-62412-5_31. hal-03024969

\section{HAL Id: hal-03024969 \\ https://imt-mines-albi.hal.science/hal-03024969}

Submitted on 20 Jan 2021

HAL is a multi-disciplinary open access archive for the deposit and dissemination of scientific research documents, whether they are published or not. The documents may come from teaching and research institutions in France or abroad, or from public or private research centers.
L'archive ouverte pluridisciplinaire HAL, est destinée au dépôt et à la diffusion de documents scientifiques de niveau recherche, publiés ou non, émanant des établissements d'enseignement et de recherche français ou étrangers, des laboratoires publics ou privés. 


\title{
Toward Physical Internet-Enabled Supply Chain and Logistics Networks in Developing Countries
}

\author{
Sam Ban ${ }^{1}$, Matthieu Lauras ${ }^{1(\bowtie)}$, and Sarot Srang ${ }^{2}$ \\ ${ }^{1}$ Industrial Engineering Department, University of Toulouse - IMT Mines Albi, \\ Campus Jarlard, 81013 Albi CT Cedex 09, France \\ \{sam.ban, matthieu. lauras\}@mines-albi.fr \\ 2 Industrial and Mechanical Engineering Department, \\ Institute of Technology of Cambodia, Russian Federation Blvd, \\ P.O. Box 86, Tuol Kouk, Phnom Penh, Cambodia \\ srangsarot@itc.edu.kh
}

\begin{abstract}
Developing countries have numerous challenges to manage in terms of supply chain and logistics networks such as safety, corruption, pollution, congestion, old and/or unsuitable vehicles, long lead times, economy, wastes and of course poor infrastructures and so on. While developed countries have started to change their mindset and toolboxes for managing their material flows all along their logistics networks, it is not yet the case for developing countries. This research work intends to study potentials benefit for these countries if there are drastic changes of the way physical of material flows are managed. In such a context, Physical Internet paradigm is considered as an interesting avenue for improvement. The objective of this paper is to draft an options that would be necessary to assess and to design the associated research methodology. Insights regarding an ongoing field-oriented research work in Cambodia are developed to highlight the potential.
\end{abstract}

Keywords: Physical Internet $\cdot$ Supply chain $\cdot$ Logistics $\cdot$ Networks $\cdot$ Developing countries $\cdot$ Cambodia

\section{Introduction}

Studies like [1] demonstrated that supply chain and logistics play an important role and contribute significantly to economic growth and competitiveness of a country. However, many developing countries have issues and challenges such as corruption and informal payments, lack of institutional capacity and coordination, poor infrastructure and low-quality transportations, weak urban-rural and cross-border transportation networks, restricted participation of the private sector, lack of skilled human resources, and low public and private investments. As mentioned by [2], identifying and solving supply chain and logistics networks problems like these are the key issues of developing countries. Despite efforts and investments that are made to improve the supply chain and logistics networks means of these countries, the problems remain critical. Basically, these countries must cope with numerous supply chain and logistics 
networks problems such as safety, corruption, pollution, congestion, old and/or unsuitable vehicles, long lead times, wastes and of course poor infrastructures. Therefore, developing countries have a major crisis on their hands [2] if they want to sustainably support their economy. This is particularly true for countries like Cambodia whose economy is mainly based on agricultural productions and distribution of imported materials. In such a context, supply chain and logistics networks must be transformed into a more efficient and effective way. In parallel, we have to consider that the supply chain and logistics networks are running to the industry 4.0 era [3]. This new time is composed of technologies such as advanced robotics, artificial intelligence (AI), blockchain, autonomous vehicles, drones or Internet of Things (IoT) for instance, and of new supply chain and logistics paradigms such as Servitization [4] or Physical Internet (PI) [5]. If most of the developed countries are involved in enhancing their supply chain and logistics networks through these approaches and technologies, developing countries are not outdone. However, there are still tons of questions about how to benefit from these new approaches and technologies in developing countries which have major issues such as poor infrastructures, transportations networks, lesstrusted logistics services, information of technology, etc. The current research work is studying this issue by investigating the potentiality of implementing PI paradigm to developing countries in order to enhance their supply chain and logistics networks capabilities. This work is divided into three sections. First section discusses some key points on the literature which focus on the latest research works. Based on author knowledge, this new idea has not been conducted yet in developing countries. The second section develops avenues for implementing PI to supply chain and logistics networks in developing countries. It also suggests a framework able to objectively assess the potential benefits and limits of them and gives some insights regarding an ongoing Cambodian case study. The last section is about conclusion and future work.

\section{Literature Review and Research Statement}

\subsection{Developing Countries Supply Chain and Logistics Networks Features}

Some research works like [6,7] or [8] studied the consequences of low performance supply chain and logistics networks in developing countries. They highlighted that the main issues came from weak capabilities regarding both human and machine means, poor track \& trace systems and poor innovative and collaborative approaches. Another report by [9] indicates that the most important factor affecting the international logistics process of African countries was limited information integration, poor infrastructures, and specific local country risks such as corruption. As shown by [10], around $98 \%$ of material flows in developing countries like Malaysia highly depend on the road while infrastructures are generally not good. On their side, [11] revealed that the port of developing countries such as Sri Lanka was lower performance of transshipment hub ports comparing to developed countries like Singapore or Netherlands. All these situations caused several issues by leading to increase cost of logistics, $\mathrm{CO}_{2}$ emission and transport time and to decrease service quality to end-customers [10]. To conclude, developing countries supply chain and logistics networks do not seem to be effective. 
Additionally, other studies demonstrated that developing countries have some issues regarding the efficiency of their supply chain and logistics networks. For instance, [12] introduced the top three factors impacting warehousing process efficiency which were labor productivity, warehouse utilization and inventory space utilization. Most of the time, logistics plants (i.e. warehouses or distribution centers) in developing countries are under-used. In parallel, [13] pointed out that the position of the country's ranking for Vietnam in the LPI fell from 48 in 2014 to 64 in 2016 due to higher logistics costs. As a result, they noted that one might pay more attentions to the efficiency of logistics service providers (LSPs) and technologies in developing countries. The increase in volume of both people and material flows in developing countries implied critical stakes regarding last-mile deliveries and urban logistics [14]. These growing processes can cause a major problem not only for the cities, but also for the countries. Inappropriate material flows and lack of supply chain and logistics networks strategies will cause an increase in the final cost of products and traffic flow deterioration. These will affect to the GDP of both developed and developing countries. Last but not least, researchers such as [15] showed that most of the developing countries did not yet adopt supply chain and logistics networks technologies like Intelligent Packaging (IP) or Internet of Thing (IoT). They found that cost and lack of knowledge were the main barriers. This is a questionable situation considering that at the same time people in developing countries are more and more used to live with connected devices such as smartphones.

\subsection{The Physical Internet Opportunity}

The original manifesto of PI consists in changing the manner in which physical items are managed, delivered, transported, stored, realized, supplied and used to achieve global logistics efficiency and sustainability [5]. In practice, PI is an emergent and innovative concept of interconnected logistics networks capitalizing on the opportunity of sharing assets and capabilities. PI totally challenges in the supply chain foundations. Nowadays, companies are part of a specific and stable network and possess their warehouses, manufacturing plants or fleets. PI takes the opposite of this view and induces that assets should be shared between all the stakeholders part of this global network and used on a need basis.

PI has now been used for many research-works to improve supply chain and logistics networks. However, most of the researches on PI have been being conducted in developed countries like Canada, USA, China, France and some other countries in Europe while developing countries have probably their own issues and challenges regarding PI implementation. [16] showed that supply chains and logistics networks are more and more intensely interconnected on multiple layers, ultimately anytime, anywhere. The interconnectivity layers notably include digital, physical, operational, business, legal and personal layers. They name this new state "hyperconnectivity".

In practice, PI paradigm already implies several innovative proposals and demonstrated its potential benefits. For instance, in the specific context of logistics and transportation in urban environment, [17] showed that the PI initiative enables hyperconnected logistics which is capable of transforming the freight transport fragmentation, logistics and distribution industries into a single manufacturing. Goods would be 
encapsulated and designed in standard for logistics that are modular, smart and reusable PI-containers, all size (from small cases up to the cases of cargo containers). [17] indicated also that these smart containers (PI container) can be routed from end to end through open hubs by developing real-time identification, tracking, and communication systems. Also, PI containers can store data or information required during different operations in terms of handling and transportation.

On their side, [18] introduced semantic technology for enabled innovative supply chain and logistics networks as adaptive synchromodal planning by improving visibility and consequently predictability of turnaround times at container terminals. The study intended to address the notion of synchromodal transport and the PI. In another research work, [19] investigated the issue of urban transportation in a PI-enabled setting by applying multiple types of vehicles. They found that PI interconnectivity and extra hubs could improve urban transport planning regarding to routing efficiency and postponed services. [20] studied the comparison of PI performance and conventional logistics system to measure the advantages and disadvantages of PI. The analysis show that PI could reduce truck driving distances, times, cost and carbon emission. Instead, it increased the number of PI-container transfers within the PI logistics centers. Inspired by PI concepts, [21] exploited the extra loading capacity of taxis to collect the reverse flows of goods in the city using simulation modelling method. Although the solution resulted in greater distances and higher lead times for the return flows compared to an ideal case. With these results, they highlighted that it was hard to directly compare between real world cases and the proposed solution of the model. The actual cases had very different selection strategies. However, they still claimed that their proposed model was more feasible in the following aspects. With another perspective, [22] introduced the mitigation of supply chain networks disruptions on hubs and factory plants and investigated the inventory model resilience through the PI framework of interconnected logistics services. They wanted to introduce PI disruption mitigation strategies by using simulation modelling technique when plants, warehouses, hubs and distribution centers became unserviceable for a period of time. The results of this technique helped to deal with disruptions in terms of penalty, transport and total costs.

\subsection{Research Statement Formulation}

The current research wants to use the concepts and technologies of the PI initiative imagined few years ago. Basically, one goal of our research is to demonstrate the potential benefits of PI in the context of developing country (economic, social and environmental dimensions) of physical object mobility.

The main idea of this research is finally to demonstrate (i) the benefits of managing transportation activities through a "connected" approach in developing countries and (ii) the feasibility of such an evolution on one hand, and in developing (iii) the first decision support tools that will allow concretizing this on the other hand.

This research has the following concrete objectives for a developing country: (i) reduce transportation lead times; (ii) improve on-time delivery ratio; (iii) avoid useless travelled distance; (iv) limit waste of goods due to bad transportation; (v) improve carriers' profitability; (vi) allow transportation multimodality; (vii) allow real 
time tracking of goods; (viii) optimize transportation costs; and (ix) reduce carbon footprint impact of transportation.

It is important to notice here that the current research work did not focus on the technological dimensions of the PI (devices and connected assets, etc.). The research work only focuses on the use of the PI paradigm to better manage the material flows in a specific context of developing countries.

\section{Proposal}

As the objective is to improve both efficiency and effectiveness of supply chain and logistics networks in developing countries, there is one obvious option that consists drastically in modernizing the infrastructures (roads, buildings, etc.) and the logistics means which are used (vehicles, IT systems, machines, etc.). But building new and modern infrastructures (underground, bridge, highway, flyover) or investing in new transportation means for instance is a very expensive and time-consuming step. Within an opposite view, our suggestion involves in thinking about potential evolutions that might be implemented now, on the basis of existing or accessible means. In the following we first suggest some recommendations for looking for such an improvement inspired by the PI paradigm. Second, we develop a methodological approach allowing us to assess the potential impacts of these different recommendations. Third, we will draft the field-research application which is ongoing in Cambodia and its expected results.

\subsection{Putting PI into Practice for Developing Countries}

Nowadays, developing countries (like other countries) are using connected devices such as smartphones boosting the network sharing through Internet connectivity. But these technologies are not used or used inappropriately on supply chain and logistics activities while it could be very useful for them. Within an hyperconnected perspective, all the supply chain and logistics networks stakeholders (suppliers, shippers, carriers, customers, etc.) could be connected altogether and allow a set of PI levers that should be implemented in developing countries.

\section{Open-Hubs Initiatives}

In the current state of supply chain and logistics networks in developing countries, the product flows are formed by suppliers (mostly from oversea), warehouses and retailers or wholesalers, market and supermarket... As normal, the physical flow goes from one actor to another directly, on a one-to-one basis and through ownership assets. Hyperconnected supply chain and logistics networks will allow more collaboration by means of multiple open hubs in different places. All of these open hubs are composed of a network and would connect each other. It will be possible for any company to access to these open hubs on demand without agreeing for a long period. This consists in applying the concept of SaaS (Software as a Service) to the supply chain and logistics networks assets. As a result, the flow of products would transit much more efficiently and effectively from one hub to another before reaching its customers, and 
benefits from mutualization of means all along the value chain. Through the web open hubs strategy, products are not committed as a priori to one plant, the products are consolidated from different sources by multiple carriers and moving toward the same direction to final customers as shown in Fig. 1. This Figure shows the comparison between a simple delivery without PI (Fig. 1(a)) and with PI (Fig. 1(b)). Basically, Fig. 1(b) considers shared warehouses, transportation assets and hyperconnected flows. Each color of the Figure represents different destinations of delivery. As a result, Fig. 1 (b) with hyperconnected could save more times and costs by reducing travel distances and maximizing utilization rate of assets. In such a context, it has been demonstrated that PI can reduce, in developed countries situation, logistics costs by about $75 \%$, carbon emission by $60 \%$ and travelled distance by $15 \%$ [17]. The remaining question is what we can expect in the context of developing countries?

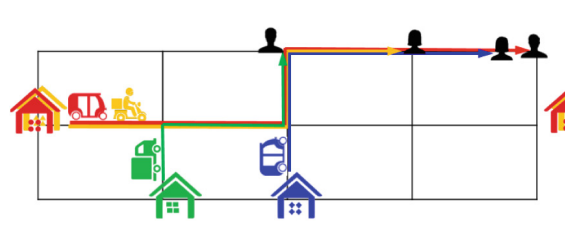

(a)

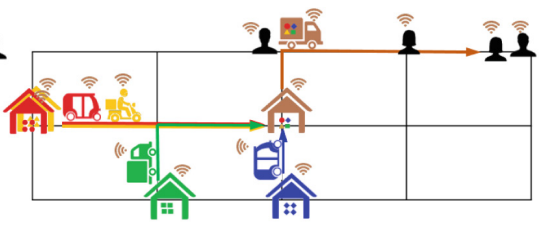

(b)

Fig. 1. Simple one-to-one flows (a) vs hyperconnected and web open hubs (b).

\section{Dynamic Transportation Chartering and Use}

As considering on the supply chains in developing countries, most of shippers and carriers are chartering dedicated vehicles which could be for material and/or people moving, for shipments from one company to another. Within a PI perspective, transportation means (such as motorcycle taxi, bajaj, tuk-tuks, taxis, vans, etc.) might be connected to a common platform in real time. Then, it would be possible to charter dynamically this or this vehicle for a delivery based on geo-localization opportunities or capacity opportunities. Additionally, deliveries might be organized as a relay race between the source and the delivery point in order to accelerate the flow, to limit the cost and better use the available capacities. As a consequence, quality improvement and cost reduction in transport seem to be possible by using modern IT systems able to support the hyperconnectivity concept. Then, an efficient combination of transport modes/vehicles can be optimized by route-planning to guarantee an efficient use of the available resources and by bundling transport streams at certain points to minimize the frequency of transports (especially in cities). Combining different transport modes (multimodal transport) could be useful for transport-quality improvement and cost reduction. The concept of synchromodality can also be seen as a first step towards the PI, synchromodality aims to create a flexible and cooperative transport network by using the different available transport resources. As a consequence, reliability, robustness and resilience of the transport network should be increased by introducing real-time monitoring of the transport chains and real-time mode and route choice. For the connection between the actors, the infrastructure and the different transport modes 
are essential for the PI and lead to a comprehensive interconnectivity. Sharing all relevant information and guaranteeing the topicality of the data in a real-time manner are also crucial elements for the concept of the PI.

\section{Dynamic Planning and Scheduling}

Within a hyperconnected perspective, we could monitor and predict all aspects in real time where the goods are, what the available vehicles are and what the current disruptions are that exist on the infrastructures. This would allow managing the material flows from suppliers to customers much more efficiently and effectively than today. In addition to this kind of behavior, one can also plan proactive measures by considering seasonality or expected or unexpected events. For instance, considering that typhoon season will start in few weeks and that this road might be flooded, then we can prepare in advance some rerouting plans or transportation mode changes. Also, we can avoid road congestion dynamically accordingly to some real-time event management. In such a context, managers would have access to a centralized transportation planning and scheduling system (see Fig. 2). Such a system could estimate their needs, by geographical zone, in terms of transportation, inventory and maybe production for the next periods. First, this would mean that decision makers will have the opportunity to negotiate capacities on-demand and on-the-fly with their providers to avoid shortage situations or brutal increase of unitary costs for instance. Second, this would mean that managers will have the possibility to assess different alternatives a priori to fit supply chain and logistics decisions with established demands and opportunities.

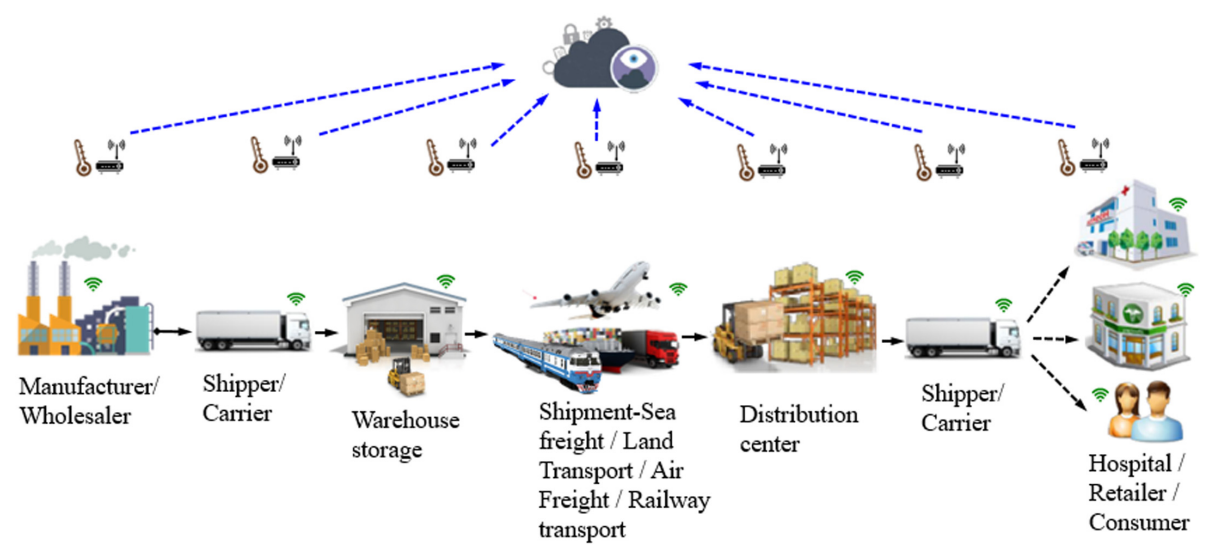

Fig. 2. PI-oriented supply chain and logistics networks for developing countries

\section{Pick-Up and Asynchronous Deliveries}

Additionally, in developing countries, majority of the material flows are home delivery. This implies important difficulties as delays and hazards are frequent. In a PI perspective, the supply chain and logistics networks might organize deliveries close to end-customers instead of parcel handed personally to increase the quality of service. Generalization of solutions such as lockers, permanent pick up points and/or temporary pick up points would be a significative change that would have to be assessed. 
Obviously, it would be hard to involve all these factors into a general supply chain model applicable for every developing country. In the following of this research, we will have to focus on a specific use case, such as Cambodia, before extending to other clusters of developing countries.

\subsection{Performance Assessment Framework}

Our suggested methodology framework is broken down into four phases:

1. Phase one is data gathering. As our research work is field-oriented, a concrete dataset is needed and has to be extracted from a real network in order to have a clear vision about the business processes and the material flows of a real system. Obviously, this step can be difficult in the context of networks that might have limited maturity in terms of legacy IT systems. Typically, the dataset that has to be gathered is composed of the following elements:

a. General features about the network and its environment: it might include information about the business model of the company, business perspectives, market positioning, etc.

b. Static features about assets which are involving in the considered Supply Chain: it might include information about vehicles, warehouses, items description, supplier description, customer descriptions, etc.

c. Dynamic features about material flows which are managed by the considered Supply Chain: it might include information about the customer orders, inventories, supplier orders, transportation orders, etc.

2. Phase two consists in analyzing the dataset to transform it into knowledge, to set the problem formulation and to build the model conceptualization. As an output of this step, we should get an accurate and exhaustive map of the studied network.

3. Phase three is related to the design of potential solutions inspired by the PI paradigm and the modelling of them onto a dynamic model able to assess quantitatively the impacts of them on the supply chain and logistics networks. In our case, we have chosen to work through a discrete event simulation approach that is currently ongoing. Basically, this phase will include modelling simulation and validation by experimen. The experiment will consist in defining scenarios that correspond to the AS-IS situation of the material flow management in a developing country use case, and to define a set of TO-BE scenarios representative of PI paradigms in order to assess potential benefits and limits of evolving in that direction.

4. Phase four consists in exploiting the simulation results obtained from the previous phase to make concrete recommendations in terms of organization for developing countries supply chain and logistics networks. Obviously, these recommendations will be made by considering both the assumptions made and the sensitivity of the used model. 


\subsection{Ongoing Field-Oriented Research}

Based on the previous framework, we are working on a Cambodian e-commerce supply chain and logistics network case. This company is located in Phnom Penh and offers apparel, footwear, bags, accessories, electronics, books, automotive, baby, kid toy, and beauty and health products. Consumers can also directly buy products from this company in 3 different stores located in Phnom Penh. The delivery services of products are made by their own employees for Phnom Penh and through $3^{\text {rd }}$ Party Logistics Providers for provinces and countryside. Customers order products every day. The delivery services are shipped these items to customer's home every day. Most of the times, the company manages the delivery services by its own employees. Currently, the company has 200 employees in total and 30 employees for delivery purpose of products to end-customers in Phnom Penh. Currently, the majority of products in warehouses and showrooms are imported from different sources of different suppliers located in Thailand, Vietnam and China. Until now there are over 100,000 items in the warehouses and shops, there are more than 1000 customer orders per day with different items of products each time. The majority of products are clothes which is $80 \%$ of the products of selling. Until now, the supply chain provides about $70 \%$ of product sales to customers in Phnom Penh and 30\% at province of Cambodia. The studied supply chain is represented on the following Fig. 3.

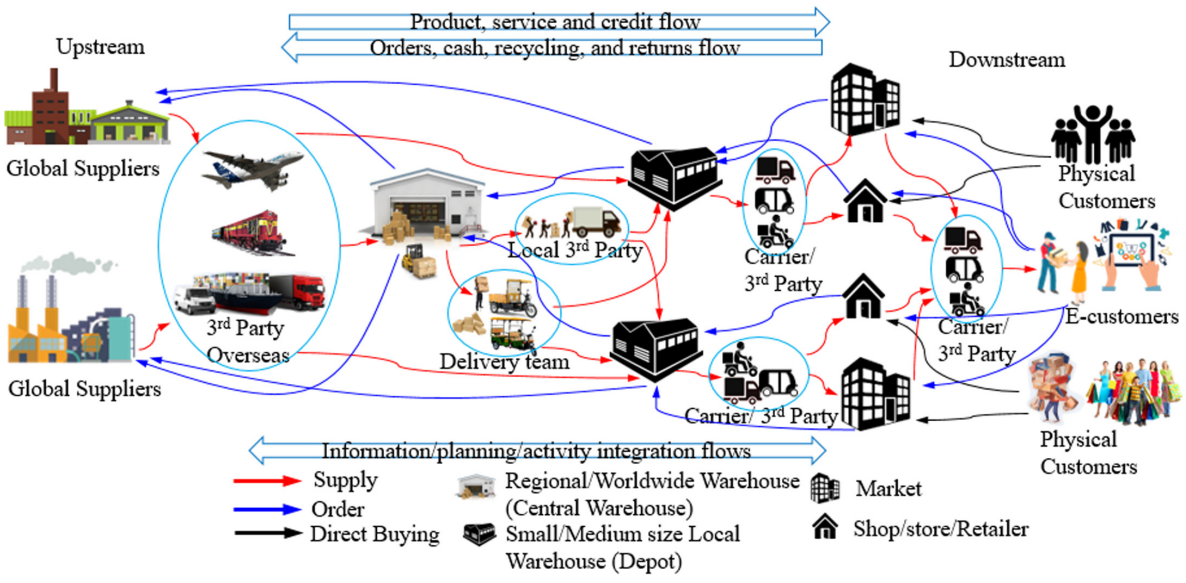

Fig. 3. Supply Chain flow map in Cambodia

At the starting point of the study, this supply chain and logistics network might be considered as very representative of a developing country's economy stakeholder. They noticed poor effectiveness of the means and resources involved in their network on one hand, and a poor efficiency of their network (numerous shortages, low quality of service, long lead-time...) on the other hand. In the following months, the current research work will intend to study the implementation of PI solutions described 
previously and to objectively assess the expected impacts for this network in terms of both effectiveness and efficiency. Significant improvements are expected.

\section{Conclusion and Research Perspectives}

While the current research work is in its infancy, we have demonstrated in this paper that developing countries supply chain and logistics networks have great stakes regarding both efficiency and effectiveness. We made the assumption that applying Physical Internet paradigm to this specific context will be useful and bring more benefits for supply chain and logistics in Cambodia. Within this objective, we suggested in this paper a set of concrete options to activate in developing countries and set the basis to make in a near future a concrete and objective assessment of them. A very first draft of an ongoing- field-oriented approach is also mentioned in this paper. Obviously, numerous research perspectives arise from this starting research work. The next steps will consist of finalizing the data gathering process with the Cambodian company in order to feed our future simulation model. Then the development of a discrete event simulation model able to mimic the existing supply chain and logistics network behaviors and to envisage the future ones, based on a PI approach, will be continued. The objective of this model will be to compare the results in terms of Supply Chain performance of developing countries' networks based on classical approaches of material flow management with the same networks running on PI basis. To do so, a structured experiment plan will have to be designed and run to get quantitative and objective results allowing us to make clear and complete recommendations.

\section{References}

1. Chheang, V.: FDI, services liberalisation, and logistics development in Cambodia. ERIA Discussion Paper Series, Services Liberalization in ASEAN: Foreign Direct Investment in Logistics Sector, 15-16 November 2016, ISEAS-Yusof Ishak Institute, 268 (2017)

2. Masood, M.T., Khan, A., Naqvi, H.A.: Transportation problems in developing countries Pakistan: a case-in-point. Int. J. Bus. Manag. 6(11), 256 (2011)

3. Tang, C.S., Veelenturf, L.P.: The strategic role of logistics in the industry 4.0 era. Transp. Res. Part E Logist. Transp. Rev. 129, 1-11 (2019)

4. Baines, T., Bigdeli, A.Z., Bustinza, O.F., Shi, V.G., Baldwin, J., Ridgway, K.: Servitization: revisiting the state-of-the-art and research priorities. Int. J. Oper. Prod. Manag. 37(2), 256278 (2017)

5. Montreuil, B., Meller, R.D., Ballot, E.: Physical internet foundations. In: Borangiu, T., Thomas, A., Trentesaux, D. (eds.) Service Orientation in Holonic and Multi Agent Manufacturing and Robotics. Studies in Computational Intelligence, vol. 472, pp. 151-166. Springer, Heidelberg (2013). https://doi.org/10.1007/978-3-642-35852-4_10

6. Ul-Hameed, W., Shabbir, M., Imran, M., Raza, A., Salman, R.: Remedies of low performance among Pakistani e-logistic companies: the role of firm's IT capability and information communication technology (ICT). Uncertain Supply Chain Manag. 7(2), 369380 (2019) 
7. MahbubulHye, A.K., Miraz, M.H., Sharif, K.I.M., Hassan, M.G.: Factors affecting on elogistic: mediating role of ICT \& technology integration in retail supply chain in Malaysia. TEST Eng. Manag. 82, 3234-3243 (2020). ISSN 0193-4120

8. Liu, Y.: A study on the factors affecting e-logistics system in Chinese logistics industry. In: 2017 2nd International Conference on Automation, Mechanical Control and Computational Engineering (AMCCE 2017). Advances in Engineering Research, vol. 118, pp: 981-984. Atlantis Press (2017)

9. Yang, C.C., Chang, Y.K.: Crucial factors influencing international logistics operations for African landlocked countries. Marit. Policy Manag. 46(8), 939-956 (2019)

10. Chen, S.L., Jeevan, J., Cahoon, S.: Malaysian container seaport-hinterland connectivity: status, challenges and strategies. Asian J. Shipping Logist. 32(3), 127-138 (2016)

11. Kavirathna, C.A., Kawasaki, T., Hanaoka, S.: Transshipment hub port competitiveness of the port of Colombo against the major Southeast Asian hub ports. Asian J. Shipping Logist. 34(2), 71-82 (2018)

12. Karim, N.H., Rahman, N.S.F.A., Shah, S.F.S.S.J.: Empirical evidence on failure factors of warehouse productivity in Malaysian logistic service sector. Asian J. Shipping Logist. 34(2), 151-160 (2018)

13. Dang, V.L., Yeo, G.T.: Weighing the key factors to improve Vietnam's logistics system. Asian J. Shipping Logist. 34(4), 308-316 (2018)

14. Rossolov, A., Lobashov, O., Kopytkov, D., Botsman, A., Lyfenko, S.: A two-echelon green supply chain for urban delivery. Sci. Tech. 18(6), 495-503 (2019)

15. Noletto, A.P.R., Loureiro, S.A., Castro, R.B., Júnior, O.F.L.: Intelligent packaging and the Internet of Things in Brazilian food supply chains: the current state and challenges. In: Freitag, M., Kotzab, H., Pannek, J. (eds.) Dynamics in Logistics. LNL, pp. 173-183. Springer, Cham (2017). https://doi.org/10.1007/978-3-319-45117-6_16

16. Montreuil, B., Ballot, E., Tremblay, W.: Modular design of physical internet transport, handling and packaging containers. In: Progress in Material Handling Research: 2014, 13th MHI, 2015, International Material Handling Research Colloquium (2015). 978-1-88278018-3. hal-01487239

17. Crainic, T.G., Montreuil, B.: Physical internet enabled hyperconnected city logistics. Transp. Res. Procedia 12, 383-398 (2016)

18. Hofman, W., Punter, M., Bastiaansen, H., Cornelisse, E., Dalmolen, S.: Semantic technology for enabling logistics innovations-towards intelligent Cargo in the physical internet. Int. J. Adv. Logist. 5(2), 58-69 (2016)

19. Ben Mohamed, I., Klibi, W., Labarthe, O., Deschamps, J.C., Babai, M.Z.: Modelling and solution approaches for the interconnected city logistics. Int. J. Prod. Res. 55(9), 2664-2684 (2017)

20. Fazili, M., Venkatadri, U., Cyrus, P., Tajbakhsh, M.: Physical Internet, conventional and hybrid logistic systems: a routing optimisation-based comparison using the Eastern Canada road network case study. Int. J. Prod. Res. 55(9), 2703-2730 (2017)

21. Chen, C., Pan, S., Wang, Z., Zhong, R.Y.: Using taxis to collect citywide E-commerce reverse flows: a crowdsourcing solution. Int. J. Prod. Res. 55(7), 1833-1844 (2017)

22. Yang, Y., Pan, S., Ballot, E.: Mitigating supply chain disruptions through interconnected logistics services in the physical internet. Int. J. Prod. Res. 55(14), 3970-3983 (2017) 